\title{
Study on Load Analysis of Propulsion System using SOM
}

\author{
Jae-Hee Jang $\circledR^{*}$ and Jin-Seok $\mathrm{Oh}^{\circledR^{*}}$ \\ "Department of marine engineering, Korea Maritime and Ocean University, Busan, Korea \\ 자기조직화지도를 이용한 추진시스템의 전력부하분석 연구 \\ 장재희 $0^{*}$ 오진석(* \\ "한국해양대학교 기관공학부
}

KEY WORDS: Load analysis 부하분석, Propulsion system 추진시스템, Self organizing map 자기조직화지도, Ship operation mode 선박 운용 모드, Container ship 컨테이너선

\begin{abstract}
Recently, environmental regulations have been strengthened for SOX, NOX, and CO2, which are ship exhaust gases. In addition, according to the 4th Industrial Revolution, research on autonomous ship technology has become active and interest in electric propulsion systems is increasing. This paper analyzes the power load characteristics of an electric propulsion ship, which is the basic technology for an autonomous ship, in terms of energy management. For the load analysis, data were collected for a 6,800 TEU container ship with a mechanical propulsion system, and the propulsion load was converted to an electric power load and clustered according to the characteristics using a SOM (Self-Organizing Map). As a result of the load analysis, it was confirmed that the load characteristics of the ship could be explained by the operation mode of the ship.
\end{abstract}

\section{1. 서 론}

최근 환경 보호를 위해 황산화물 $\left(\mathrm{SO}_{\mathrm{x}}\right)$, 질소산화물 $\left(\mathrm{NO}_{\mathrm{x}}\right)$, 이 산화탄소 $\left(\mathrm{CO}_{2}\right)$ 등의 선박 배출가스에 대한 환경 규제가 강화되 고 있으며 이를 만족하기 위해서 친환경 선박 기술에 대한 관 심이 늘어나고 있다. 친환경 선박 기술은 선박에서 배출되는 배
기오염물질을 줄이는 것에서부터, 선박의 에너지 효율을 높임 으로써 배기오염물질의 발생을 줄이는 기술을 포함한다(Park et al., 2016). 선박의 에너지 효율을 높이는 기술로는 선박의 에너 지를 관리하는 $\mathrm{EMS}($ Energy management system)가 있다. EMS는 발전기와 배터리간의 에너지 분배를 통해 발전기의 효율을 높 이는 LCS(Load control system)을 포함하고 있어 선박의 부하상

Table 1 Advantages and disadvantages of mechanical propulsion system and electric propulsion system

\begin{tabular}{|c|c|c|}
\hline Pros an cons & Mechanical propulsion system & Electric propulsion system \\
\hline Design flexibility & - Engine room layout limited by main shaft & $\begin{array}{l}\text { - Has flexibility in main engine layout } \\
\text { - Engine room volume is reduced, resultingly cargo load } \\
\text { increases }\end{array}$ \\
\hline Ship control ease & $\begin{array}{l}\text { - The power generated by the prime mover is transmitted } \\
\text { to the propeller shaft and drives the propeller, thereby } \\
\text { deteriorating the propulsion performance }\end{array}$ & $\begin{array}{l}\text { - Since the electric propulsion motor is driven, the steering } \\
\text { performance is improved (Automated, intelligent) }\end{array}$ \\
\hline Energy efficiency & $\begin{array}{l}\text { - Since it is connected directly to the propeller through the } \\
\text { shaft in the prime mover, there is only mechanical loss } \\
\text { occurring in the shaft. }\end{array}$ & $\begin{array}{l}\text { - There is a conversion loss because it is converted to the } \\
\text { electric power from the prime mover and then converted } \\
\text { into the propulsion power at the electric motor } \\
\text { - Energy efficiency can be improved by controlling the load } \\
\text { on the generator }\end{array}$ \\
\hline $\begin{array}{l}\text { Environment } \\
\text { friendly }\end{array}$ & $\begin{array}{l}\text { - Emissions of } \mathrm{SOX}, \mathrm{CO} 2, \mathrm{PM} \text {, etc. are high, because mainly } \\
\text { using fuel oil for ships. }\end{array}$ & $\begin{array}{l}\text { - Advantage in terms of reducing exhaust gas through high } \\
\text { efficiency operation of generator and battery application }\end{array}$ \\
\hline
\end{tabular}

Received 31 January 2019, revised 16 September 2019, accepted 16 October 2019

Corresponding author Jin-Seok Oh : +82-51-410-4283, ojs@kmou.ac.kr ORCID: https://orcid.org/0000-0003-3627-476X

This is an open access article distributed under the terms of the creative commons attribution non-commercial license (http://creativecommons.org/licenses/by-nc/3.0) which permits unrestricted non-commercial use, distribution, and reproduction in any medium, provided the original work is properly cited. 
태를 모니터링하고 관리하는 기술이 요구된다. 또한, 조선 해양 분야의 4차 산업혁명 기술로 대표되는 자율운항 선박은 모니터 링 및 제어 용이성으로 전기추진이 추천되고 있으며(Park et al., 2018), 전기추진시스템은 배출가스 및 소음이 적은 면에서 친환 경 기조와 부합한다. Table 1을 통해 기계식 추진시스템과 전기 추진시스템의 설계 유연성 및 조종성과 에너지 효율 및 친환경 성을 비교하였다(Im et al. 2011).

전기추진시스템에는 추진부하가 전력시스템에 통합되면서 기 존의 기계식 추진시스템과는 다른 부하특성을 보이게 된다. 본 연구에서는 전기추진시스템의 부하특성을 분석하기 위해서 6,800TEU 컨테이너선의 추진부하 및 전력부하를 수집하고, 자기 조직화지도를 이용하여 부하분석을 수행한다. 신경망, 전문가 시 스템이 부하분석에 사용될 수 있으며, 가시적으로 확인 가능한 측면에서 자기조직화지도를 사용하였다. 부하 분석을 분석된 부 하특성은 $\mathrm{EMS}$ 를 통한 에너지 관리 및 제어에 활용이 가능하다. 에너지의 관리적 측면에서 부하를 예측하여 배터리에 저장 및 사용을 통하여 유연성 있도록 운용이 가능하며, 제어적 측면에 서는 불필요한 발전기의 대수를 줄여 효율을 높일 수 있다.

\section{2. 데이터 수집}

본 연구에서는 $6,800 \mathrm{TEU}$ 컨테이너선의 추진부하와 전력부하 데이터를 수집하여 부하분석에 활용한다. 대상선박인 $6,800 \mathrm{TEU}$ 컨테이너선은 기계식추진시스템으로 추진부하를 전력부하로 변 환하여 부하분석을 진행하였다. Table 2 는 데이터 수집 대상선 박의 제원을 나타낸다.

Table 2 Specification of target ship

\begin{tabular}{cc}
\hline \hline Type & Container ship \\
\hline Length & $299 \mathrm{~m}$ \\
Width & $40 \mathrm{~m}$ \\
Draft & $13.5 \mathrm{~m}$ \\
Engine output & $68,520 \mathrm{~kW}(93,120 \mathrm{Bhp})$ \\
Generator output & $3,000 \mathrm{~kW} \times 4$ \\
Maximum speed & $12.86 \mathrm{~m} / \mathrm{s}(25 \mathrm{knot})$ \\
TEU / number of reefer container & $6,732 / 550$ \\
\hline
\end{tabular}

\section{1 데이터 개요}

선박 부하분석을 목적으로 발전기의 출력, 부하율 등의 전력 데이터와 엔진의 출력, 속도 등의 데이터를 수집하였다. 데이터 는 약 411 일간 수집되었으며, 데이터의 수집주기는 10 분이다. Table 3은 수집한 데이터를 정리한 표이다.

\section{2 수집 데이터의 특징과 항차별 분류}

수집된 데이터는 411일 간의 데이터로 이 중 항차로 구분이 가능한 것은 총 55 항차에 해당된다. 항차는 출항-항해-입항-정 박을 한 항차로 정의하였다. 411일 간의 데이터를 항차로 구분 한 것은 항차 별 선박의 운용모드를 탐색을 용이하게 하기 위 한 목적이다.
Table 3 Acquisition data list

\begin{tabular}{ccc}
\hline \hline No. & Signal & Unit \\
\hline 1 & Data acquisition time & YYYY-MM-DD-TT \\
2 & No. 1 generator load & $\mathrm{kW}$ \\
3 & No. 1 generator load ratio & $\%$ \\
4 & No. 1 generator run/stop & $1 / 0$ \\
5 & No. 2 generator load & $\mathrm{kW}$ \\
6 & No. 2 generator load ratio & $\%$ \\
7 & No. 2 generator run/stop & $1 / 0$ \\
8 & No. 3 generator load & $\mathrm{kW}$ \\
9 & No. 3 generator load ratio & $\%$ \\
10 & No. 3 generator run/stop & $1 / 0$ \\
11 & No. 4 generator load & $\mathrm{kW}$ \\
12 & No. 4 generator load ratio & $\%$ \\
13 & No. 4 generator run/stop & $1 / 0$ \\
14 & Main engine run/stop & $1 / 0$ \\
15 & Ship speed & $\mathrm{knot}(1 \mathrm{knot} \fallingdotseq 0.51 \mathrm{~m} / \mathrm{s})$ \\
16 & Main engine torque & $\mathrm{kgfm}$ \\
17 & Main engine shaft speed & $\mathrm{r} / \mathrm{min}$ \\
18 & Main engine break horse power & $(1 \mathrm{hp} \fallingdotseq 0.75 \mathrm{~kW})$ \\
\hline
\end{tabular}

선박의 운용모드는 기본적으로는 항해(Seagoing), 입출항(Port in/out), 정박(Harbour)으로 나누어진다. 여기에 컨테이너선의 경 우 선하적(Load/Unload 또는 Cargo handling) 등 선박의 목적과 기능에 따라 운용모드가 추가된다. 이와 같이 선박에 따른 운용 모드 구분은 설계단계의 부하분석(Load analysis)에서 정의하는 모드에 따른다. 부하분석은 선박의 부하에 대해서 선박 내 부하 사용을 부하의 운용율을 나타내는 부하계수(Load factor)와 정격 부하를 사용하여 나타내며, 선박의 운용모드에 따라 구분되어 발전기 용량선정, 배전반 설계, 전력케이블 크기 선정 등 전력 시스템의 설계자료로 활용된다. 본 논문에서는 수집한 411일 간 55 항차에 해당하는 선박데이터를 군집분석을 통해 선박의 운용 모드와 비교하였다.

\section{3 엔진 출력 데이터의 처리}

데이터를 수집한 대상선박은 디젤엔진을 주기관으로 사용하 는 기계식 추진시스템으로, 기계식 추진시스템과 전기추진시스 템은 구성 장비와 동력 전달 방법에 차이가 있다. 기계식 추진 시스템은 원동기에서 발생한 출력을 축으로 전달하여 추진기에 서 추력을 발생시키는 반면 전기추진시스템은 발전기로 생산한 전력을 추진전동기에서 동력으로 변환하여 추진기에서 추력을 발생 시킨다. 전기추진시스템이 더 많은 에너지 변환을 거치게 되며, 따라서 변환효율 측면에서 기계식추진시스템보다 효율이 떨어진다. 본 연구에서는 수집한 대상선박의 데이터에 전기추 진시스템의 변환효율을 고려하기 위해 Fig. 1과 같이 엔진 사용 시 효율과 추진전동기 사용이 효율을 비교하여 적용하였다 (MAN, 2012). 


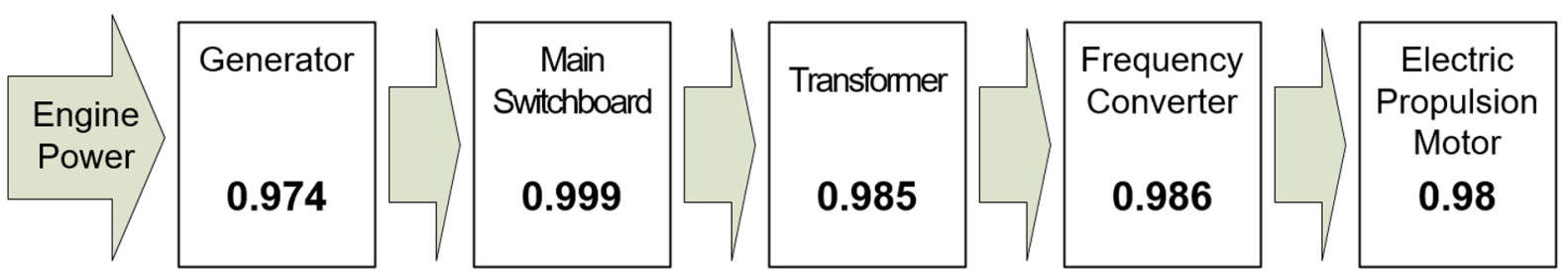

Fig. 1 Energy conversion efficiency of electric propulsion system

엔진 사용 시 효율은 축 효율인 0.97 을 적용하였고, 추진전동 기 사용 시 효율은 발전기 효율과 변환기 효율, 추진전동기 효 율 및 축 효율을 고려하여 0.89 를 적용하였다. 수집한 데이터는 축 효율이 적용된 데이터이므로 엔진 사용 시 효율을 제하고 추진전동기 사용 시 효율을 적용하여 식 (1)와 같이 나타내었다.

$$
P_{e \cdot p}=0.75 \times \eta_{c} \times P_{m \cdot p}
$$

여기서, $P_{e . p}$ 는 추진부하(추진전동기) [kW], $\eta_{c}$ 는 변환효율 [무차 원수]로 0.92 를 적용하였으며, $P_{m \cdot p}$ 는 추진부하(엔진) [hp ( $1 \mathrm{hp} \fallingdotseq$ $0.75 \mathrm{~kW}$ )]이다.

\section{3. 자기조직화지도를 이용한 군집분석}

\section{1 데이터 마이닝 개요}

데이터 마이닝(Data mining)은 데이터를 대상으로 통계적 규 칙이나 패턴을 찾아내는 방법을 의미한다. 데이터 마이닝 기법 중 인공신경망(Artificial neural network)을 기반으로 하는 방식으 로는 자기조직화지도(Self organizing map, SOM), 신경망, 전문가 시스템 등이 있다. 데이터 마이닝은 다음과 같은 목적으로 활용 이 된다.

(1) 분류(Classification) : 데이터를 정의된 특성으로 분류한다.

(2) 군집화(Clustering) : 다양한 특성을 갖는 데이터에 대해서 유 사한 특징을 가진 데이터를 군집으로 만들어 분류한다. 분류 와 차이점으로 군집화의 경우 특성을 정의하지 않는다.

(3) 연관성 분석(Association analysis) : 데이터에 존재하는 관 계를 찾아낸다.

(4) 연속성 분석(Sequencing analysis) : 특정 기간을 갖는 데이 터에 대해서 관계를 찾아낸다.

(5)예측(Forecasting) : 데이터의 패턴을 바탕으로 하여 다음 데 이터를 예측한다.

이 중 군집분석은(Cluster analysis)은 다변량 데이터를 특성에 따라 군집화하여 특성을 파악할 수 있다. 군집의 개수가 결정되 지 않았거나, 특성을 알 수 없는 초기 데이터에 대해서 군집화 를 통해 데이터간의 유사성 정도를 판단하면 데이터 분포와 구 조 이해의 목적으로 활용이 가능하다. 분류와 비교하였을 때 군 집화의 장점으로는 군집의 특성과 개수가 파악되지 상태에서 사용할 수 있다는 점이다. 따라서 데이터 분석 초기단계에서 사 용하여 데이터 간의 유의성 판단, 구조 이해의 목적으로 활용이 된다.
본 연구에서는 군집분석을 통해 선박에서 측정한 데이터간의 관계를 군집화하여 수집한 전력데이터와 선박 운용 모드와의 유의성을 판단하고, 그 결과를 부하제어 알고리즘에서 사용할 데이터 변수 선정에 활용한다. 부하제어 알고리즘에서는 정박 시에 사용하는 크레인, 입출항시 사용하는 스러스터 등의 중부 하의 운용이 영향을 미치므로 선박의 운용 모드가 확인되어야 한다. 따라서 본 논문에서는 선박의 부하 변화 및 선속 데이터 를 수집하고 군집분석을 통하여 현재 선박의 운용모드 판단에 활용하도록 하였다.

\section{2 자기조직화지도}

자기조직화지도는 1980년대 핀란드의 공학자 코호넨(Teuvo Kohonen)에 의해 개발된 인공신경망의 일종으로 비지도학습 (Unsupervised learning)에 의한 클러스터링 방법 중 하나이다 (Kohonen, 1990). 자기조직화지도의 가장 큰 특징은 시각화 (Visualization)와 축약화(Abstraction)로, 다차원 입력데이터에 대 하여 데이터간의 유의성을 2 차원에서 시각적으로 확인이 가능 한 점이다. 또한 별도의 피드백이나 지도 없이 자체적으로 학습 을 진행하여 경쟁학습을 통해 고차원의 데이터를 저차원의 지 도에 변환시켜 나타낼 수 있다. 자기조직화 지도는 경쟁학습을 통해 활성화시킬 출력 노드를 선택하는 과정에서 노드를 서로 경쟁시켜 하나의 출력 뉴런을 선택한다. 이때 선택된 뉴런을 승 자 뉴런이라고 하며, 입력벡터와 거리 값이 최소인 노드를 선택 하고, 선택된 노드와 주변 노드에 대해서 가중치를 수정해가면 서 학습이 진행된다. 일련의 과정을 벡터 값의 변화가 거의 없 거나 지정한 학습 횟수에 도달할 때까지 반복하여 수행한다. Fig. 2는 자기조직화지도의 학습 개념을 설명한다.

자기조직화지도는 입력층(Input layer)과 경쟁층(Competition layer), 그리고 최종 출력층(Output layer)으로 나누어진다. 입력 층은 표본 데이터로부터 얻어진 다차원 데이터로 $n$ 개의 $p$ 차원 입력개체(Input unit)로 구성된다. 각 입력개체에는 가중치 벡터

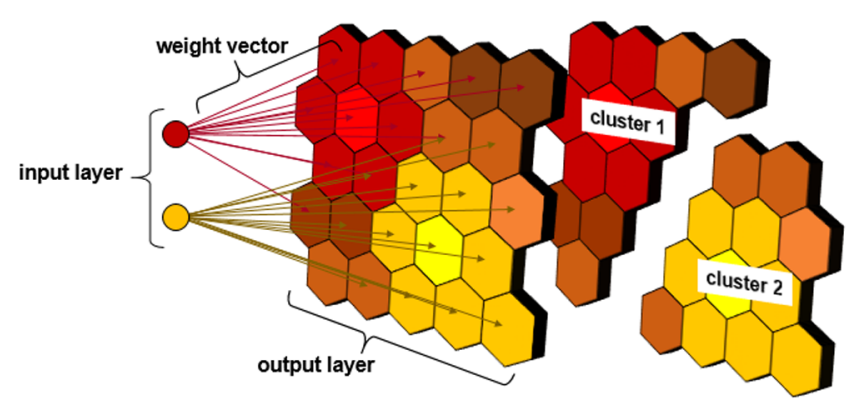

Fig. 2 Concept of low dimensional map transformation of SOM (Kohonen, 1990) 
(Weight vector)가 초기화과정을 거쳐 임의값으로 입력된다. 가 중치 벡터의 초기화 방법은 선형 초기화(Linear initialization)와 무작위 초기화(Random initialization)가 있다.

\section{3 자기조직화지도의 최적노드수 선정}

자기조직화지도를 수행하기 위해서는 데이터 개수에 적합한 노드수를 입력해야한다. 본 연구에서는 데이터의 개수에 따라 격자개수를 선정하였으며, 데이터 개수에 따라 비대칭 격자 구 성을 활용하였다. 격자 개수는 식 (2)로 구할 수 있다(Ahn et al., 2018).

$$
M \approx 5 \sqrt{N}
$$

여기서, $M$ 은 격자 개수 [개], $N$ 은 대상의 관측 데이터 개수 [개] 를 의미하며, 이에 따라서 Table 4와 같이 데이터 개수에 대해 서 격자 개수를 선정한다.

\section{4 자기조직화지도의 수행결과}

총 55항차에 대해서 자기조직화지도를 수행하였다. 군집화에 사용한 데이터는 보조부하, 추진부하, 전체부하, 보조부하 비율, 추진부하 비율, 선속이다. 군집화를 통해 부하의 특징과 변수간 의 연관성을 도출한다. Fig. 3 은 항차 1 에 대한 선박의 보조부

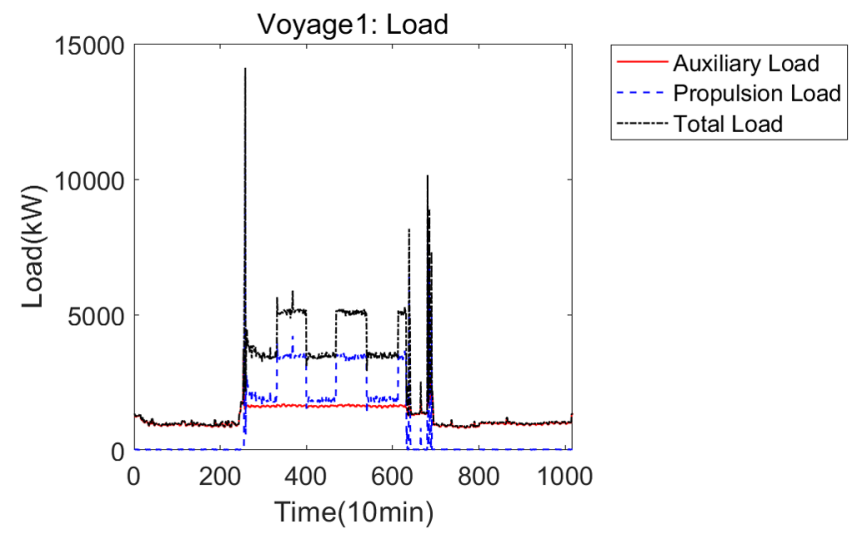

Fig. 3 Total power load of ship on voyage 1

하, 추진부하, 전체부하의 변화를 나타낸다. 가로축은 10 분 간격 으로 측정한 데이터의 누적시간을 의미하고, 세로축은 부하를 의미한다. 항차 1 에서는 2,550 분에서 6,950 분까지 추진전력을 사용하여 항해를 하였다.

Fig. 4는 입력한 데이터에 대해서 자기조직화지도를 수행한 결과이다. 가로 및 세로축은 데이터 격자의 위치를 나타내며, 격자 사이의 색상 변화는 격자 간의 거리를 나타낸다. 황색에서 적색을 거쳐 흑색으로 갈수록 군집간의 거리가 멀다. 항차 1 은 크게 3 개의 군집으로 나누어질 수 있다. 항차 1 외 총 55 항차에

Table 4 Selection of grid according to voyage case

\begin{tabular}{|c|c|c|}
\hline Voyage & Number of data & Number of grid \\
\hline 1 & 1017 & $10 \times 16$ \\
\hline 2 & 339 & $9 \times 10$ \\
\hline 3 & 697 & $11 \times 12$ \\
\hline 4 & 552 & $9 \times 13$ \\
\hline 5 & 88 & $6 \times 8$ \\
\hline 6 & 423 & $8 \times 13$ \\
\hline 7 & 264 & $9 \times 9$ \\
\hline 8 & 196 & $7 \times 10$ \\
\hline 9 & 117 & $6 \times 9$ \\
\hline 10 & 652 & $9 \times 14$ \\
\hline 11 & 118 & $6 \times 9$ \\
\hline 12 & 135 & $7 \times 9$ \\
\hline 13 & 645 & $9 \times 14$ \\
\hline 14 & 674 & $10 \times 13$ \\
\hline 15 & 276 & $7 \times 12$ \\
\hline 16 & 78 & $5 \times 9$ \\
\hline 17 & 81 & $5 \times 9$ \\
\hline 18 & 123 & $7 \times 8$ \\
\hline 19 & 267 & $9 \times 9$ \\
\hline 20 & 973 & $12 \times 13$ \\
\hline 21 & 175 & $6 \times 11$ \\
\hline 22 & 1582 & $11 \times 18$ \\
\hline 23 & 623 & $9 \times 14$ \\
\hline 24 & 1884 & $12 \times 18$ \\
\hline 25 & 601 & $11 \times 11$ \\
\hline 26 & 397 & $9 \times 11$ \\
\hline 27 & 392 & $9 \times 11$ \\
\hline
\end{tabular}

\begin{tabular}{|c|c|c|}
\hline Voyage & Number of data & Number of grid \\
\hline 29 & 943 & $11 \times 14$ \\
\hline 30 & 1598 & $10 \times 20$ \\
\hline 31 & 139 & $6 \times 10$ \\
\hline 32 & 629 & $9 \times 14$ \\
\hline 33 & 1243 & $11 \times 16$ \\
\hline 34 & 625 & $9 \times 14$ \\
\hline 35 & 531 & $9 \times 13$ \\
\hline 36 & 247 & $6 \times 13$ \\
\hline 37 & 179 & $6 \times 11$ \\
\hline 38 & 600 & $11 \times 11$ \\
\hline 39 & 387 & $7 \times 14$ \\
\hline 40 & 276 & $7 \times 12$ \\
\hline 41 & 255 & $8 \times 10$ \\
\hline 42 & 83 & $5 \times 9$ \\
\hline 43 & 664 & $10 \times 13$ \\
\hline 44 & 177 & $6 \times 11$ \\
\hline 45 & 83 & $5 \times 9$ \\
\hline 46 & 145 & $6 \times 10$ \\
\hline 47 & 335 & $7 \times 13$ \\
\hline 48 & 293 & $6 \times 14$ \\
\hline 49 & 973 & $12 \times 13$ \\
\hline 50 & 197 & $7 \times 10$ \\
\hline 51 & 1417 & $10 \times 19$ \\
\hline 52 & 132 & $7 \times 8$ \\
\hline 53 & 240 & $7 \times 11$ \\
\hline 54 & 758 & $10 \times 14$ \\
\hline 55 & 1342 & $13 \times 14$ \\
\hline
\end{tabular}




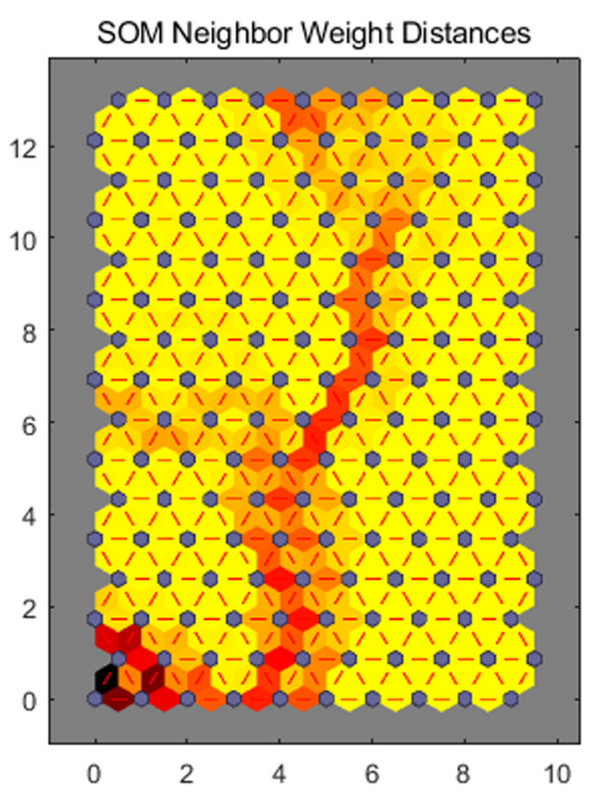

Fig. 4 Neighbor Weight Distances of voyage 1

대해서 자기조직화지도를 수행한 결과 항차별 2 4개의 군집으 로 분류가 가능하였다.

Fig. 5는 입력한 데이터의 분포를 나타내고 있다. 가로 및 세 로축은 데이터 격자의 위치를 나타내며, 격자 색상은 데이터 분 포 정도를 나타낸다. 왼쪽 상단에서부터 보조부하, 추진부하, 전 체부하, 보조부하비, 추진부하비, 선속으로 황색에 가까울수록 값이 큰 데이터가 분포하고 있음을 나타낸다.

보조부하 비율과 추진부하 비율을 통해서 선박의 운용 모드 를 확인할 수 있다. 보조부하비와 추진부하비는 서로 반비례 관
계로, 맵 상에서 보조부하비가 크게 나타나는 구역이 정박상태 에 해당되고, 추진부하비가 크게 나타나는 구역이 항해상태를 나타낸다. Fig. 5(a) 맵에서 보조부하는 정박상태에서보다 항해 상태에서 부하의 크기가 크게 나타나지만 차이가 크지 않다. Fig. 5(b) 맵에서 사용된 추진부하의 크기는 크게 두 개의 군집 으로 구별될 수 있다. Fig. 5(c)의 전체부하와 추진부하 맵이 유 사하게 나타나는 것은 전체부하에서 추진부하의 비율이 높기 때문으로 추진부하가 전체부하의 70 80\%를 차지하는 전기추진 시스템의 특징 때문으로 확인된다. 선속의 경우 군집 경계에서 값이 크게 변하고 있으며 이는 입출항 상태에서 선속의 변화 때문으로 확인된다. 선속의 변화가 큰 구역에서 보조부하가 크 게 나타나는 격자가 존재하는데 입출항 시 사용하는 바우스러 스터 때문이다.

\section{4. 결과 분석}

\section{1 전체항차 분석}

55항차에 대한 자기조직화지도 결과에 대해서 각 클러스터 별로 가장 많은 데이터를 가진 격자의 특징을 추출하여 선박 운용 특성을 분석하였다. 클러스터의 특성과 빈도를 고려하고 자 각 항차별로 10 개 격자를 대상으로 총 550 개의 격자에서 보 조부하, 추진부하, 전체부하, 보조부하비, 추진부하비, 선속 데 이터를 추출하였다. 보조부하, 추진부하, 전체부하, 보조부하비, 추진부하비, 선속 클러스터 데이터간의 상관관계를 보다 쉽게 확인하기 위해서 전체부하를 기준으로 데이터를 오름차순 정렬 하여 데이터간의 상관관계를 확인하였다. Fig. 6은 전체 부하의 변화에 따른 보조부하와 추진부하의 크기 및 비율을 나타내고, Fig. 7은 전체 부하의 변화에 따른 선속과 보조부하 및 추진부 하의 크기를 나타낸다.

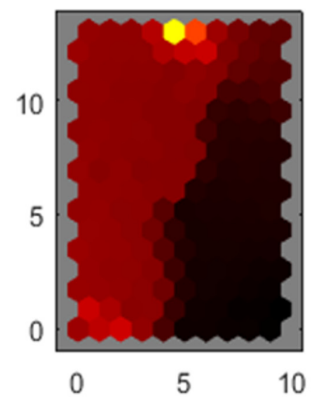

(a) Auxiliary load

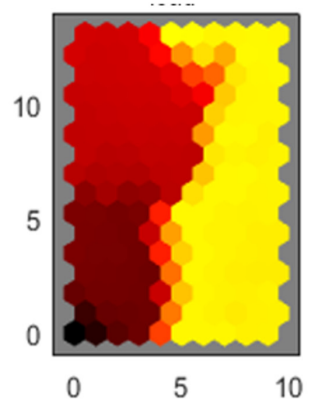

(d) Ratio of auxiliary load

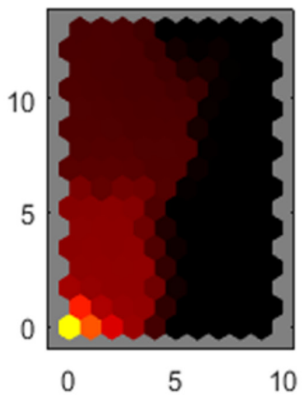

(b) Propulsion load

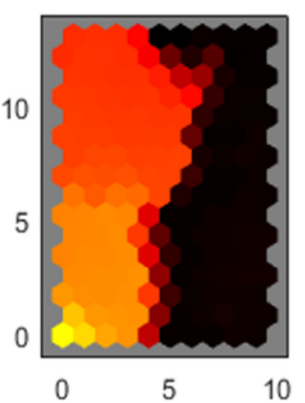

(e) Ratio of propulsion load

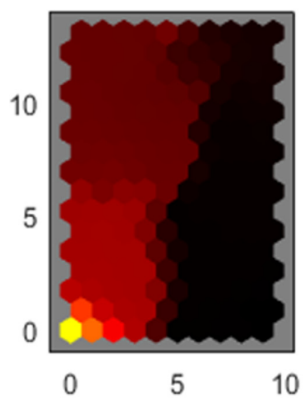

(c) Total load

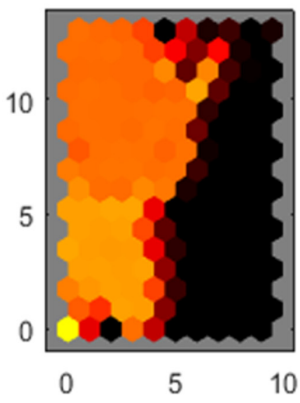

(f) Ship speed

Fig. 5 Input planes of voyage 1 


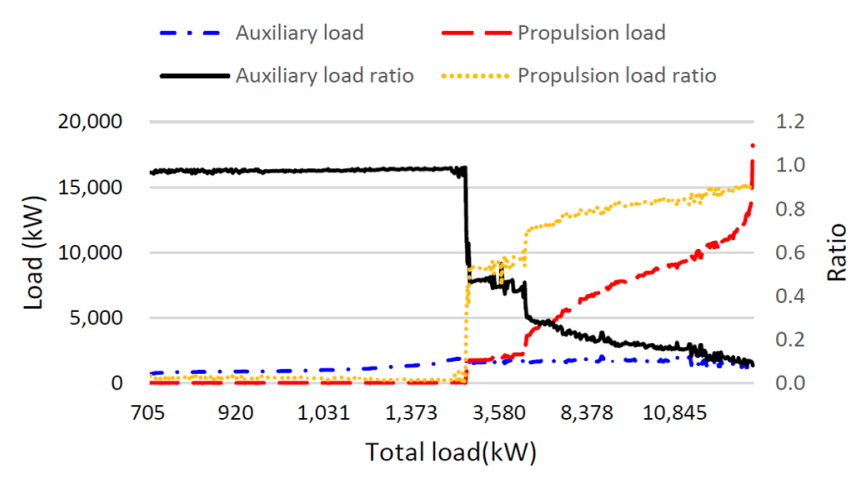

Fig. 6 Load and load ratio due to changes in total load

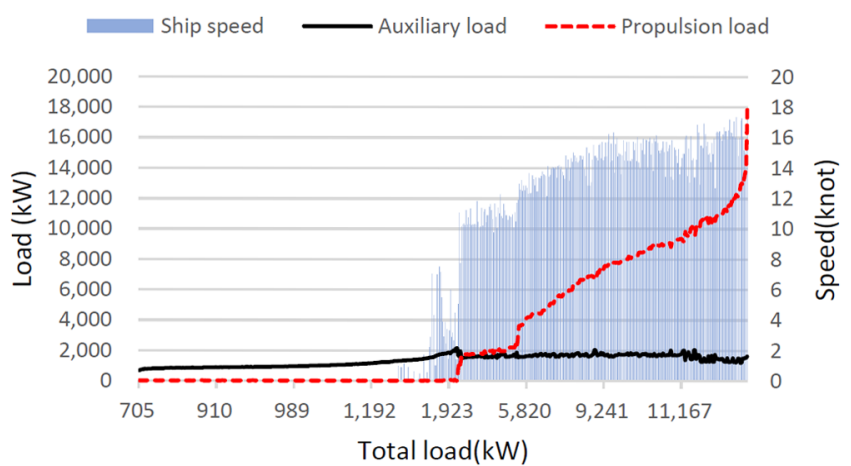

Fig. 7 Load and ship speed due to changes in total load

보조부하의 경우 추진부하와 비교하여 전체부하에 따른 변동 이 작은 것으로 확인된다. 반면 추진부하는 전체부하가 증가하 면 큰 폭으로 증가하게 되며, 따라서 전체 부하가 큰 구간에서 는 추진부하가 높은 비율을 차지하게 된다.

전체부하가 작은 구간에서는 선속도 느리게 나타난다. 선속이 0 일 때는 선박의 운용 모드로는 정박 상태라고 판단이 가능하 며, 추진부하가 거의 존재하지 않는 상태로 보조부하가 전체부 하의 $98 \%$ 이상을 차지하고 있다. 선속이 발생하면서 추진부하 가 없는 구간은 관성에 의해 선속이 유지되었거나 바우스러스 터에 의한 선속이 발생한 상태로 판단할 수 있으며, 보조부하가 증가하는 추세를 보인다. 이후 추진부하가 발생한 구간에서 보 조부하는 다시 감소하며 이후 거의 일정한 부하를 유지한다. 추 진부하는 선속이 증가함에 따라 함께 증가하는 추세를 보이나 같은 추진부하에서도 선속의 변화가 큰 편이다. 이는 해상상태 와 타(Rudder)의 사용에 따라 달라지는 것으로 판단된다.

Fig. 8과 Fig. 9는 각각 보조부하율의 변화에 따른 전력 변화 와 추진부하율에 따른 전력변화를 나타내고 있다. 보조부하율

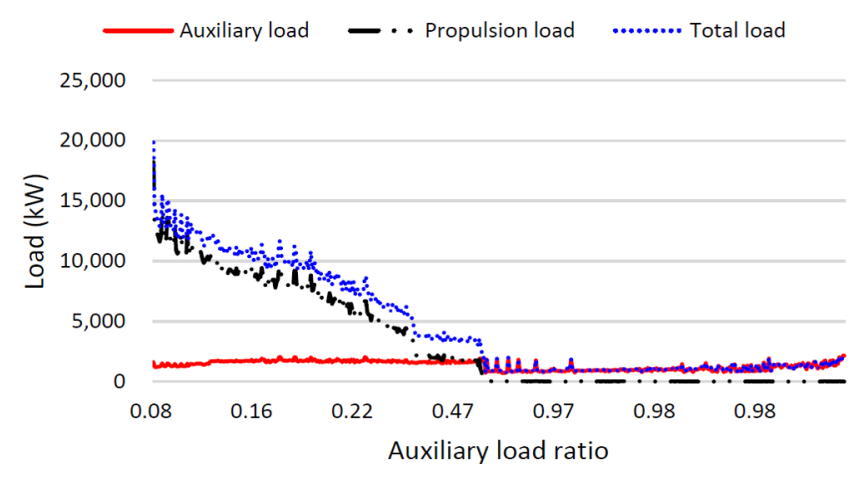

Fig. 8 Load change due to the variation of the auxiliary load ratio

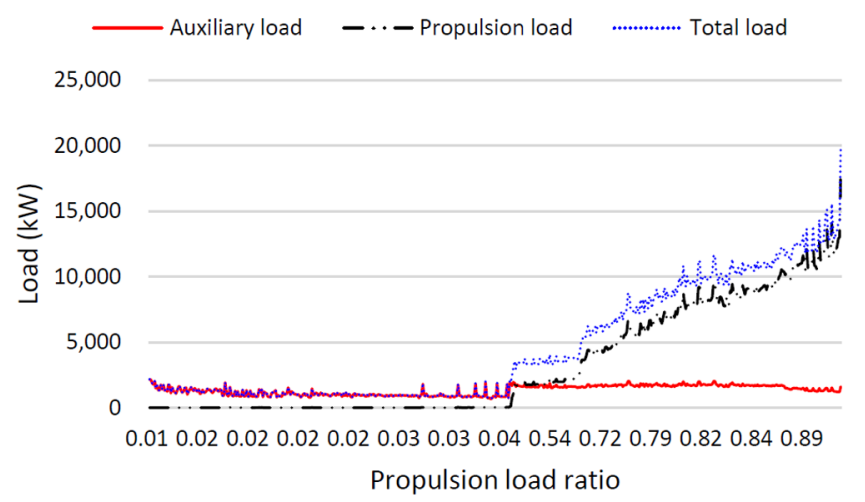

Fig. 9 Load change due to the variation of the propulsion load ratio

이 낮고 추진부하율이 높은 구간에서 전체부하는 추진부하를 따라가며, 보조부하율이 높고 추진부하율이 낮은 구간에서는 전체부하는 보조부하를 따라가게 된다. 또한 추진부하의 비율 이 높아질수록 부하의 변동 폭이 커지기 때문에 이 경우, 선박 의 전력 시스템은 여유 전력을 충분히 확보해야한다.

추진부하가 전체부하에서 높은 비율을 차지하는 경우, 부하의 변동이 크게 발생한다고 판단되며 부하 변동에 대응하기 위해 서 충분한 여유 전력 확보가 필요하다. 전기추진시스템에서는 여유전력 확보를 위해서 발전기 부하율에 여유를 두거나 배터 리를 설치하여 충전한 전력을 사용할 수 있다.

\section{5. 선박데이터를 이용한 부하 모드 선정}

부하 특성에 따른 모드는 크게 세 가지로 나눌 수 있으며, 이 는 선박의 운용 모드로 설명이 가능하다. Table 5는 선박 운용 의 세 가지 모드에 대한 보조부하와 추진부하 및 전체부하의

Table 5 Characteristic equation of mode of propulsion system operation

\begin{tabular}{|c|c|c|c|c|c|c|c|c|c|c|c|c|}
\hline \multirow{2}{*}{ Load Mode } & \multicolumn{4}{|c|}{ Mode_S } & \multicolumn{4}{|c|}{ Mode_H } & \multicolumn{4}{|c|}{ Mode_P } \\
\hline & $\min$ & average & $\max$ & variance & $\min$ & average & $\max$ & variance & $\min$ & average & $\max$ & variance \\
\hline $\begin{array}{l}\text { Auxiliary } \\
\text { load }[\mathrm{kW}]\end{array}$ & 1,215 & 1,656 & 2,037 & 172 & 1,507 & 1,638 & 1,952 & 96 & 682 & 1,083 & 2,157 & 287 \\
\hline $\begin{array}{l}\text { Propulsion } \\
\text { load }[\mathrm{kW}]\end{array}$ & 3,612 & 8,152 & 1,8220 & 2,492 & 777 & 1,097 & 4,436 & 1,451 & 16 & 24 & 101 & 9 \\
\hline $\begin{array}{c}\text { Total load } \\
{[\mathrm{kW}]}\end{array}$ & 5,202 & 9,808 & 19,846 & 2,413 & 2,476 & 3,555 & 4,436 & 303 & 705 & 1,108 & 2,177 & 291 \\
\hline
\end{tabular}


Table 6 Modes of propulsion system operation

\begin{tabular}{cccc}
\hline \hline Mode & Mode_P & Mode_H & Mode_S \\
\hline Ratio of propulsion load [\%] & $0 \sim 5$ & $31 \sim 65$ & $69 \sim 92$ \\
Ratio of auxiliary load [\%] & $95 \sim 100$ & $35 \sim 69$ & $8 \sim 31$ \\
\hline
\end{tabular}

특성에 대해서 정리한 표이다.

자기조직화지도 수행 결과를 바탕으로 모드를 구분하였다. 첫 번째 모드의 특성은 항해 중에 주로 나타나는 특성으로 Mode_S(Seagoing), 두 번째 모드의 특성은 입출항 중에 주로 나 타나는 특성으로 Mode_H(Harbour), 세 번째 모드의 특성은 정 박상태에서 주로 나타나는 특성으로 Mode_P(Port)로 정하였다. 각 모드별 특성은 Table 6과 같다.

(1) Mode_P : 정박상태로 대표되는 모드로, 전체 부하의 대부 분이 보조부하이며 따라서 변동 특성 또한 보조부하를 따라간 다. 다른 모드와 비교하여 보조부하의 변동율이 가장 크다. 이 는 입출항으로 넘어가는 단계 또는 추진시스템이 동작하고 있 지만 선속이 측정되지 않은 상태로 확인된다.

(2) Mode_H : 입출항상태로 대표되는 모드로, 추진부하와 보 조부하의 비율이 비슷하다. 전체 운항시간에서 차지하는 비율 이 가장 작다. 추진부하의 변동율이 크게 나타난다.

(3) Mode_S : 항해상태로 대표되는 모드로, 전체 부하의 대부 분이 추진부하로 구성되어 변동 특성 또한 추진부하를 따라간 다. 전체부하 및 추진부하의 변동율이 가장 크게 나타난다. 전 체부하에서 추진시스템이 차지하는 비율은 62 92\%이다. 동일 한 선속에서도 다양한 추진전력을 보이며, 추진시스템에 의한 부하 변동이 크기 때문에 여유 전력을 충분히 확보해야 한다.

\section{6. 결 론}

본 연구에서는 $6,800 \mathrm{TEU}$ 컨테이너선에서 수집한 부하데이터 를 자기조직화지도를 이용하여 보조부하, 추진부하, 전체부하, 선속 등의 특성으로 군집화하여 부하의 특징을 분석하였다. 그 결과, 선박의 부하에 따라 선박의 모드를 크게 정박, 입출항, 항 해로 구분할 수 있었다. 정박모드에서는 보조부하만 사용되어 부하의 변화가 거의 없었으며, 입출항모드에서는 부하의 변동 량이 크고 보조부하와 추진부하의 비율이 비슷하게 나타났다. 항해모드에서는 부하변동이 선속에 영향을 받았으며, 이는 전 기추진시스템에서 추진부하의 영향이 크기 때문으로 시스템의 특성으로 확인된다.

선박 부하 데이터의 군집분석을 통한 운용모드의 확인은 선 박 내 에너지 제어 및 절감을 목적으로 하는 알고리즘에 활용 될 수 있다. 선박의 운용모드에 따라 사용하는 장비가 달라지므 로 부하의 특성이 차이가 나므로 현재 운용모드를 확인하고, 발 전기 여유율 또는 배터리 충방전을 결정할 수 있다. 또는 배출 가스 규제구역에 대하여 ‘입출항' 혹은 ‘정박' 상태를 확인하고 배터리 운용을 증가시키는 등의 판단이 가능해진다.
자기조직화지도를 이용한 부하분석은 선박에 설치된 장비나 장비의 용량이 다른 선박에도 적용할 수 있으며 선종에 따른 사용 부하나 온도 등의 환경조건 또한 부하특성에 반영될 수 있다. 따라서 선박의 운용모드에 따른 에너지 관리 시 사용자의 운항모드 입력이 아닌 선박 부하데이터를 모니터링하여 선박의 운용모드 선정이 가능하다. 본 연구에서는 선박의 추진부하 및 전력부하, 선속 등의 데이터를 수집하여 분석하였으나, 향후 추 가적인 데이터 수집 환경 구성 및 연구를 통해 외기 온도, 청수 온도 등의 환경 데이터를 획득 및 분석하여 선박의 효율적인 에너지 제어에 활용할 수 있을 것으로 사료된다. 또한 본 연구 결과를 활용하여 선박의 에너지관리를 위한 알고리즘 설계 등 에 활용이 가능할 것으로 보인다. 선박의 운용모드에 따라서 전 력소모변화에 따른 여유전력 산정 및 현재 발전 효율점을 계산 하여 알고리즘 설계에 활용이 가능하다.

\section{후 기}

본 연구는 2018년 대한민국 교육부와 한국연구재단의 지원을 받아 수행된 연구임(NRF-2018R1D1A1B07049361)

\section{References}

Ahn, H.J., Shin, J.Y., Jeong, C.S., Heo, J.H., 2018. Assessing Applicability of Self-organizing Map for Regional Rainfall Frequency Analysis in South Korea. Journal of Korea Water Resources Association, 51(5), 383-393. https://doi.org/10.3741/ JKWRA.2018.51.5.383

MAN, 2012. Diesel-electric Propulsion Plants: A brief guideline how to engineer a diesel-electric propulsion system. [Online] (Updated 2012) Available at: <https://marine.mandieselturbo. com/docs/librariesprovider6/marine-broschures/diesel-electricdrives-guideline.pdf $>$ [Accessed January 2019].

Im, J.G., Jeon, H.J., Kim, T.I., Lee, Y.K., Kim, J.H., 2011. Future Ship and Advent of its Business Model. Basic Research Report, Korea Maritime Institute.

Kohonen, T., 1990. The self-organizing map. Proceedings of the IEEE, 78(9), 1464-1480. https://doi.org/10.1109/5.58325

Park, H.S., Lee, H.C., Lee, H.J., Kim, B.R., 2016. A Study on the Policy for Enlargement Application of Eco-friendly Technology for Korean Ships. Basic Research Report, Korea Maritime Institute.

Park, H.S., Park, H.R., Heo, S.R., Lee, H.J., Kim, B.R., 2018. Autonomous Vessels, Power of New Growth for Downturned Marine Transportation and Shipbuilding Industries. Weekly Report, Korea Maritime Institute. 